\title{
PROTOCOLO DE EXPOSIÇÃO AO RISCO OCUPACIONAL DOS QUIMIOTERÁPICOS: O ENTENDIMENTO DA EQUIPE MULTIPROFISSIONAL DE UM HOSPITAL DA REGIÃO SUL DE SANTA CATARINA
}

\author{
DANDARA SILVA WALTER ${ }^{1}$ \\ KELLI PAZETO DELLA GIUSTINA ${ }^{2}$ \\ MORGANA SILVA DELL CANALE ${ }^{3}$
}

\section{CÂNCER}

O câncer é um processo patológico que começa quando uma célula normal é transformada pela mutação genética do DNA (ácido desoxirribonucleico) celular e começa se proliferar de maneira anormal. As células adquirem características invasivas, com consequentes alterações nos tecidos circunvizinhos, podendo acessar os vasos sanguíneos e linfáticos os quais as transportam até outras regiões do corpo, o que é denominado metástase, ou seja, disseminação do câncer para outras partes do corpo (PARO; PARO; FERRERA, 2005; OLIVEIRA et al, 2010).

As modalidades de tratamento são várias, incluindo a radioterapia, quimioterapia e cirurgia. $O$ tratamento depende do tipo de tumor, seu comportamento biológico, localização, extensão, idade e condições gerais do paciente, no entanto, deve atender as necessidades físicas, psicológicas e sociais do mesmo (COSTA; LIMA, 2002). O câncer, em sua fase inicial, pode ser controlado e/ou curado por meio do tratamento cirúrgico, quando este é o tratamento indicado para o caso, podendo ser aplicado com finalidade curativa ou paliativa (BRASIL, 2015a). Outra forma de tratamento é a radioterapia, que consiste em um método de tratamento local ou loco-regional do câncer. A técnica mais utilizada consiste na aplicação diária de uma dose de radiação, durante um intervalo de tempo pré-

\footnotetext{
${ }^{1} 1$ Acad. Enfermagem. Centro Universitário Barriga Verde_UNIBAVE. dady_sw@hotmail.com 2 MSc. Enfermeira. Centro Universitário Barriga Verde_UNIBAVE. kellipdg@gmail.com 3 Acad. Enfermagem. Centro Universitário Barriga Verde_UNIBAVE. morgana81@hotmail.com
} 
determinado, a partir de uma fonte de irradiação localizada longe do organismo (BRASIL, 2013).

A quimioterapia é o termo originalmente usado para descrever o uso de substâncias químicas sintéticas para destruir agentes infecciosos (HANG et al., 2007). Este termo se aplica também aos agentes capazes de destruir ou inibir o crescimento das células cancerígenas, sendo denominados por tanto de quimioterápicos antineoplásicos (sejam eles quimioterápicos propriamente ditos, hormonioterápicos, bioterápicos, imunoterápicos ou alvoterápicos) (BRASIL, 2013). As medicações quimioterápicas (antineoplásicas) são aplicadas, em sua maioria, via endovenosa, podendo também ser administrados por via oral, intramuscular, subcutânea, tópica e intratecal (BRASIL, 2015a).

A manipulação e a aplicação do medicamento podem ocorrer em espaços diferentes. Mas ambos precisam estar adequados, conforme o manual de normas técnicas e administrativas para a manipulação segura de quimioterápicos, estabelecidas pelo Instituto Nacional do Câncer (INCA) do Ministério da Saúde (BRASIL, 1995).

\section{QUIMIOTERÁPICOS E SEU RISCO OCUPACIONAL}

As drogas citostáticas se dividem em diferentes classes de acordo com sua interferência no metabolismo celular, bem como sua constituição química. As principais classes são: alquilantes, antimetabolitos, alcaloides de plantas, antibióticos, antitumorais, enzimas, metálicas e outras (BARROS, 2015).

Esses tipos de medicações podem apresentar riscos ocupacionais durante os processos de preparo, transporte, administração e descarte, diante disso, a equipe multiprofissional deve ter cuidados específicos. Maia coloca que:

Os efeitos decorrentes da exposição aos quimioterápicos podem ser imediatos (dermatite, hiperpigmentação da pele e outros) ou tardios (alopécia parcial, anormalidades cromossômicas e aumento do risco de desenvolver câncer). Ressalta-se que os efeitos carcinogênicos de tais substâncias são difíceis de demonstrar, uma vez que os cânceres, na maioria dos casos se manifestam clinicamente a partir dos 20 a 30 anos após a primeira exposição química (MAIA, 2009, p. 28). 
Em um estudo realizado por Xelegati (2006), os quimioterápicos foram citados como os principais agentes químicos responsáveis por alterações à saúde de enfermeiros.

A NR-32, Norma Regulamentadora de Segurança e Saúde no Trabalho em Serviço de Saúde, também ressalta a exposição a agentes quimioterápicos como um dos principais riscos ocupacionais que os profissionais de enfermagem enfrentam no contexto do processo de trabalho hospitalar (BRASIL, 2004).

\section{EQUIPE MULTIPROFISSIONAL NO AMBULATÓRIO DE QUIMIOTERAPIA}

Acerca dos recursos humanos, o setor de quimioterapia deve possuir: Recepcionista/Escriturária/Faturista; Médico Oncologista; Enfermeiro; Técnico de Enfermagem; Farmacêutico; Psicólogo e Higienizador (COSTA; COSTA, 2015). Além disso, pode contar com os serviços de Auxiliar de Farmácia, Fonoaudiólogo, Fisioterapeuta, Assistente Social, Terapeuta Ocupacional, etc.

Apesar da equipe profissional do setor de quimioterapia abranger profissionais de diversas áreas, não são todos que estão expostos ao risco ocupacional dos quimioterápicos e, mesmo os que estão direta ou indiretamente relacionados ao risco ocupacional, possuem diferentes graus de exposição e risco de contaminação.

Sendo assim, os enfermeiros, técnicos de enfermagem e farmacêuticos foram os profissionais enfoque da pesquisa, no que tange ao conhecimento e rotina do risco ocupacional.

\section{PROCEDIMENTOS METODOLÓGICOS}

A presente pesquisa classifica-se como descritiva, ou seja, faz uma investigação empírica, com o objetivo de conferir hipóteses, delinear um problema, analisar um fato, avaliar um programa e isolar variáveis principais (CARNEVALLI; MIGUEL, 2015).

Possui abordagem qualitativa, a qual se constitui como meio para explorar e entender o significado que os indivíduos ou os grupos atribuem a um problema social ou humano (RUIZ, 2002; MARCONI; LAKATOS, 2010). 
Trata-se de uma pesquisa documental em que, segundo Marconi e Lakatos (2005, p. 176), "[...] a característica da pesquisa documental é que a fonte de coleta de dados está restrita a documentos, escritos ou não". Os documentos pesquisados foram os protocolos de exposição ao risco ocupacional do setor de quimioterapia e farmácia de manipulação, verificados por meio de um checklist padrão elaborado previamente.

Esta pesquisa pode ser definida ainda como de campo, já que "[...] a pesquisa de campo é aquela utilizada com o objetivo de conseguir informações e/ou conhecimentos acerca de um problema, para o qual se procura uma resposta [...]". (MARCONI; LAKATOS, 2005, p. 188).

O presente estudo foi realizado em uma instituição hospitalar de grande porte, localizada em um município do Sul do Estado de Santa Catarina (SC), mais especificamente no setor de quimioterapia. Trata-se de um hospital geral, que possui serviço de alta complexidade em oncologia, ou seja, conta com serviços de cirurgia oncológica, quimioterapia e radioterapia.

Para a pesquisa, foram abordados os seguintes profissionais: 2 enfermeiras, 4 técnicas em enfermagem, 3 farmacêutica e 1 técnica em enfermagem que trabalha no laboratório de manipulação. Apesar de o ambulatório contar com mais profissionais, estes não estão expostos a risco ocupacional por manipulação e administração de quimioterápicos, portanto não fizeram parte da amostra. Assim, a pesquisa possui uma amostra intencional, ou seja, "[...] o pesquisador deliberadamente escolhe alguns elementos para fazer parte da amostra, com base no seu julgamento de aqueles serem representativos da população" (REIS, 2015, p. 6). Este tipo de amostragem é bastante usado em estudos qualitativos.

Para a coleta de dados foi confeccionado um questionário com perguntas fechadas e abertas (misto), relacionadas com os objetivos da pesquisa, envolvendo perguntas quanto às atribuições dos profissionais do setor, exposição a drogas quimioterápicas e conhecimento dos profissionais acerca da quimioterapia e seu risco ocupacional. Segundo Gil (2011, p. 130), "Questionário é uma técnica de investigação composta por um número mais ou menos elevado de questões apresentadas por escrito às pessoas, tendo o conhecimento de suas opiniões".

Para verificação teórico-prática dos protocolos utilizados no setor foi aplicado um checklist de normas técnicas de biossegurança individual, coletiva e ambiental em face dos quimioterápicos, preconizado pelo Instituto Nacional do 
Câncer - INCA (BRASIL, 1995), caracterizando a parte documental da pesquisa. Esse checklist foi preenchido durante o período de coleta de dados com a equipe multiprofissional e leitura do protocolo, no próprio ambulatório de quimioterapia e áreas adjacentes.

A pesquisa foi realizada no próprio ambiente de trabalho da equipe, em horário comumente acordado com os profissionais, sem que a aplicação do questionário interferisse em suas atividades.

Este estudo atendeu os preceitos éticos constantes na Resolução n.ำ 466, de 12 de dezembro de 2012, do Conselho Nacional de Saúde (BRASIL, 2012). O projeto foi avaliado pelos Comitês de Ética em Pesquisa da instituição de ensino e da instituição hospitalar, sob pareceres $n^{0 s}$. CAAE (Certificado de Apresentação para Apreciação Ética) 46209915.0.0000.5598 e CAAE 46209915.0.3001.5364, respectivamente.

\section{RESULTADOS E DISCUSSÃO}

Para análise de dados desta pesquisa, utilizou-se a categorização proposta por Minayo (GOMES, 2004), tendo como categoria principal, os protocolos de exposição a drogas quimioterápicas. De acordo com esta categoria, foi aplicado um checklist dos protocolos nacionais constantes no INCA aos protocolos institucionais e setoriais (farmácia de manipulação e do setor de quimioterapia), possibilitando o levantamento teóricoprático dos protocolos utilizados no setor de estudo. Diante deste checklist contatouse que os setores pesquisados não possuem Procedimento Operacional Padrão (POP) referente às normas de segurança relativas ao manuseio de pacientes em sua integralidade como preconiza o INCA. Porém possuem normas de segurança relativas ao pessoal, em que fala da limitação do número de trabalhadores que manipulam os quimioterápicos, ou seja, o setor de quimioterapia possui protocolo específico sobre o número limitado de profissionais que devem atuar, obrigatoriedade do uso de Equipamentos de Proteção Individual (EPl's) e demais restrições do setor, porém observou-se a falta de incentivo aos profissionais para manuseá-los.

No que se refere a protocolos que contemplem os possíveis riscos aos profissionais, todos os entrevistados confirmaram a sua existência, porém não 
souberam especificar; alguns relataram não terem acesso aos documentos. Diante disso, observa-se a necessidade de uma abordagem diferenciada por parte do empregador, o qual poderia incentivar os profissionais a acessarem estes documentos, a aderi-los e a participarem ativamente na formulação dos mesmos. Confirmou-se a presença de protocolos que contemplem cuidados relativos aos pacientes, abrangendo cuidados com o extravasamento de quimioterapia vesicante, irritante e derramamentos, porém os profissionais entrevistados não souberam especificá-los.

No caso da farmácia de manipulação, de acordo com os profissionais farmacêuticos, há também protocolos sobre a lavagem das mãos, limpeza da capela, transporte de quimioterápico, manipulação e contaminação ambiental. Sendo que foi possível confirmar a presença de POP's na farmácia de manipulação e setor de quimioterapia referentes a contaminação ambiental e pessoal, bem como de protocolos que dizem respeito às exigências do empregador frente aos trabalhadores do setor de quimioterapia e também da farmácia de manipulação. No entanto não houve confirmação de protocolos que contemplem em sua totalidade a saúde do trabalhador. Observou-se que estes recebem a avaliação médica anual sendo solicitada a realização do exame hematológico completo. Todavia, alguns exames que aparecem no checklist não são realizados, como: prova de funções hepática, renal e pulmonar.

Em conformidade com as medidas de segurança preconizadas INCA, percebeu-se que há um local exclusivo para o preparo das drogas, tratando-se de um ambiente tranquilo, sem corrente de ar, restrito aos funcionários do setor. Porém a estrutura física e as barreiras físicas encontravam-se irregulares devido ao andamento de obras de reforma afim de adequar-se às normas de segurança no preparo de quimioterápicos previstos na RDC 220/2004. Com base na observação dos setores pesquisados e aplicação do checklist baseado nas normas preconizadas pelo INCA, constatou-se que estas não são seguidas em sua totalidade. Por meio da aplicação do questionário evidenciou-se tal fato, uma vez que os profissionais apresentaram conhecimentos parciais do que realmente exige nos POP's do setor.

\section{CONCLUSÃO}


Através da aplicação do checklist foi possível identificar os principais protocolos aplicados aos setores de quimioterapia e farmácia de manipulação, bem como identificar quais não condizem com os documentos pré- estabelecidos pelo INCA. Ao analisar os resultados do estudo quanto aos protocolos, destacou-se o conhecimento insuficiente acerca dos mesmos, por parte dos profissionais do setor, bem como das medidas a serem tomadas em caso de contaminação. Diante disso, observa-se a necessidade de uma abordagem diferenciada por parte do empregador, o qual poderia incentivar os profissionais a acessarem estes documentos, a aderi-los e a participarem ativamente na formulação dos mesmos, objetivando aprimorar o conhecimento relacionado principalmente ao risco ocupacional e incentivo aos trabalhadores a participarem ativamente da formulação e atualização dos POP's.

\section{REFERÊNCIAS}

BARROS, I.M. Quimioterapia Antineoplásica - Riscos Ocupacionais. Niterói, 2015. Disponível em:<http://pfarma.com.br/biosseguranca/113-quimioterapiaantineoplasica-riscos-ocupacionais.html>. Acesso em: 27 abr. 2015.

BRASIL. ANVISA. Agência Nacional de Vigilância Sanitária. Resolução - RDC n. ${ }^{\circ}$ 220, de 21 de setembro de 2004: Regulamento Técnico de Funcionamento dos Serviços de Terapia Antineoplásica. Diário Oficial da União №. 184, Poder Execultivo, Brasília, DF, 21 set. 2004. Disponível em: <http://portal.anvisa.gov.br/wps/portal/anvisa/home>. Acesso em: 10 out. 2015.

INCA. Instituto Nacional do Câncer. Ação de enfermagem para controle do câncer. Rio de Janeiro: PRO-ONCO, 1995, p. 149- 150. 240p. . Disponível em:

<http://www2.inca.gov.br/wps/wcm/connect/inca/portal/home/resultado_google?siteur I=www2.inca.gov.br\%22Fwcm\%2Fconnect\%enfermagem+para+controle+do+c\%C3 \%A2ncer+1995\&sa=Pesquisar $>$. Acesso em 01 de jun. 2015.

INCA. Instituto Nacional do Câncer. Manual de Bases Técnicas da Oncologia - Sistema de Informações Ambulatoriais, ed. 14. Ministério da Saúde, Brasília, DF, abr. 2013. Disponível em:< http://www.inca.gov.br/wps/wcm/connect/agencianoticias/site/home/noticias/2010/lan cada_11_edicao_manual_bases_tecnicas_oncologia>. Acesso em: 08 out. 2015.

INCA. Instituto Nacional do Câncer. Tratamento Cirúrgico. Ministério da Saúde, Brasília, DF, 2015a. Disponível em: <http://www.inca.gov.br/conteudo_view.asp?id=98>. Acesso em: 23 abr. 2015. 
Resolução n.. 466, de 12 de dezembro de 2012. Conselho Nacional de Saúde. Dispõe sobre as diretrizes e normas regulamentadoras de pesquisas envolvendo seres humanos. Brasília, DF, 12 dez. 2012. Disponível em: <http://conselho.saude.gov.br/resolucoes/2012/Reso466.pdf>. Acesso em 23 abr. 2015.

CARNEVALLI, J.A.; MIGUEL, P.A.C. Desenvolvimento da Pesquisa de Campo, Amostra e Questionário para Realização de um Estudo Tipo Survey Sobre a Aplicação do QFD no Brasil. 2015. Disponível em:

<http://etecagricoladeiguape.com.br/projetousp/Biblioteca/ENEGEP2001_TR21_067 2.pdf>. Acesso em: 28 mar. 2015.

COSTA, L.C., COSTA, R.E.L.F. Central de Quimioterapia: Aspectos Básicos de Gerenciamento. Revista da Sociedade Brasileira de Cancerologia. 2015.

Disponível em: <http://pfarma.com.br/biosseguranca/112-central-de-quimioterapiaaspectos-basicos-de-gerenciamento.html>. Acesso em: 23 abr. 2015.

COSTA, J.C.; LIMA, R.A.G. Crianças/adolescentes em quimioterapia ambulatorial: implicações para enfermagem. Revista Latino Americana de Enfermagem, v. 10, n. 3, maio-jun 2002.

GIL, A.C. Métodos e Técnicas de Pesquisa Social. 6 ed. São Paulo: Atlas, 2011.

GOMES, R. A análise de dados em pesquisa qualitativa. In: MINAYO, Maria Cecília de Souza (Org.); DESLANDES, Suely Ferreira; NETO, Otávio Cruz; GOMES, Romeu. Pesquisa Social: Teoria, Método e Criatividade. 23. ed. Petrópolis, RJ: Vozes, p. 67-80, 2004.

HANG, H. P. et al. Farmacologia. Rio de Janeiro: Elsevier, 2007.

MAIA, P.G. A atividade da equipe de enfermagem e os riscos relacionados à exposição a quimioterápicos antineoplásicos no setor de oncologia de um hospital público do estado do Rio de Janeiro. Rio de Janeiro: Escola Nacional de Saúde Pública Sergio Arouca, 144 p. 2009.

MARCONI, A.M.; LAKATOS, M.E. Fundamentos de Metodologia Científica. 7 ed. São Paulo: Atlas S.A, 2010.

Fundamentos de Metodologia Científica. 6 ed. São Paulo: Atlas S.A, 2005.

PARO, D.; PARO, J. ; FERREIRA, D. L. M. O enfermeiro e o cuidar em Oncologia Pediátrica. Arquivo Ciências da Saúde, v.12, n.3, p. 151-57, jul-set 2005.

REIS, M.M. Amostragem. Departamento de Informática e Estatística (INE) UFSC, cap. 7, p.6, 2015. Disponível em: <http://www.inf.ufsc.br/ marcelo/Cap7.pd>. Acesso em: 01 jun. 2015. 
RUIZ, A.J. Metodologia Científica: Guia para eficiência nos estudos. 5 ed. São Paulo: Atlas S.A, 2002.

XELEGATI, R. et al. Riscos Ocupacionais químicos identificados por enfermeiros que trabalham em ambiente hospitalar. Revista Latino Americana de Enfermagem, v. 14, n. 2, p. 214-219, 2006. 